\title{
Successful practice in early career networks: insights from the polar sciences
}

\author{
Pascal Bohleber ${ }^{1,6}$, Mathieu Casado ${ }^{1,2,7}$, Kirsti Ashworth ${ }^{3,8}$, Chelsey A. Baker ${ }^{4,9, a}$, Anna Belcher ${ }^{4,10}$, \\ Jilda Alicia Caccavo ${ }^{2,11,12}$, Holly E. Jenkins ${ }^{4,9}$, Erin Satterthwaite ${ }^{5,13}$, Andrea Spolaor ${ }^{2,14}$, and \\ V. Holly L. Winton ${ }^{1,10,15}$ \\ ${ }^{1}$ Ice Core Young Scientists (ICYS) \\ ${ }^{2}$ Association of Polar Early Career Scientists (APECS) \\ ${ }^{3}$ UK Future Earth Early Career Researchers and Practitioners Network \\ ${ }^{4}$ UK Polar Network (UKPN) \\ ${ }^{5}$ Future Earth, School of Global Environmental Sustainability, Colorado State University, \\ 108 Johnson Dr, Fort Collins, CO 80523, USA \\ ${ }^{6}$ Department of Environmental Sciences, Informatics and Statistics, Ca'Foscari University of Venice, \\ Via Torino 155, 30172 Mestre, Venice, Italy \\ ${ }^{7}$ Alfred Wegener Institute Helmholtz Centre for Polar and Marine Research, \\ Telegrafenberg A45-2N, Potsdam, 14473, Germany \\ ${ }^{8}$ Lancaster Environment Centre, Lancaster University, Lancaster, UK \\ ${ }^{9}$ Department of Ocean and Earth Science, University of Southampton, Southampton, UK \\ ${ }^{10}$ British Antarctic Survey, Cambridge, UK \\ ${ }^{11}$ Berlin Center for Genomics in Biodiversity Research, Koenigin-Luise-Str. 6-8, 14195 Berlin, Germany \\ ${ }^{12}$ Alfred Wegener Institute Helmholtz Centre for Polar and Marine Research, \\ Am Handelshafen 12, 27570 Bremerhaven, Germany \\ ${ }^{13}$ National Center for Ecological Analysis and Synthesis, 735 State St, Santa Barbara, CA 93101, USA \\ ${ }^{14}$ Institute of Polar Sciences, ISP-CNR, Campus Scientifico Via Torino 155, 30172 Mestre, Venice, Italy \\ ${ }^{15}$ Antarctic Research Centre, Victoria University of Wellington, Wellington, New Zealand \\ anow at: National Oceanography Centre, Southampton, UK
}

Correspondence: Mathieu Casado (mathieu.casado@gmail.com)

Received: 30 November 2019 - Accepted: 5 March 2020 - Published: 27 March 2020

\begin{abstract}
Acquiring not only field-specific knowledge but also a set of transferable professional skills becomes increasingly important for Early Career Scientists (ECS) in Geosciences and other academic disciplines. Although the need for training in transferable skills adds to the work-load of an individual Early Career Scientist, it is often neglected within the traditional academic environments. International Early Career Networks (ECN) are global voluntary communities of early career scientists aiming (i) to advocate for early stage researchers; and (ii) to advance the careers of their members by raising their profiles and training them in specific transferable skills, such as networking, collaborating and outreach. Accordingly, ECN can be a tool to move beyond institutional barriers and to improve the inclusion of
\end{abstract}

ECS into the international scientific community. In 2019 we conducted three surveys in order to assess ECN from the perspective of its members and regarding the structures of different ECN within a specific discipline and across disciplines. We use the survey results alongside with case studies from well-established and long term networks to elucidate the attributes that make a successful, sustainable ECN. Important characteristics of these international ECN include (1) developing the ECN organizational schemes to promote early career scientists within a specific discipline and across disciplines, (2) scoping for members needs, evaluating the performance of the network, and adapting to feedback, (3) continuity of the organizing committee by ensuring representation of different stages of ECS, and (4) diverse membership to pro- 
vide strong foundational and personnel support within the network. These characteristics can support the development of best practices for developing ECN successfully, which can guide existing and future networks within Geosciences and other scientific disciplines.

\section{Introduction}

Early Career Scientists $\left(\mathrm{ECS}^{1}\right)$ are professionals recently trained in their discipline, but who have not been working in their field for an extended amount of time. Since ECS represent the emerging new generation in their discipline, it is important to equip ECS with the support, professional development, and skills necessary to advance their career and further enhance their contribution to the scientific community. Although there is no precise definition of an "Early Career Scientist", a commonly accepted framework encompasses university students (bachelor, master and $\mathrm{PhD}$ students), postdoctoral researchers and Early Career professionals (assistant professor or lecturer, research associate). As a specific example of a project call for scientists in their early career stage, the European Union considers the time limit to apply for a starting grant no longer than 7 years after $\mathrm{PhD}$ completion. In case of career breaks and part-time working, an extension equal to the time spent away from academia can be granted.

Early Career Scientists ${ }^{2}$ are a critical part of the work force in science (Taylor and Francis, 2015) and participate at all levels of the production of scientific knowledge, including hypothesis testing, grant writing, data analysis and synthesis, publication and project management. ECS also participate in extensive professional training, working to acquire the necessary skill set to effectively integrate into the scientific community. Acquiring not only field-specific know-how but also a set of transferable and "soft" skills has become increasingly important for ECS - such as networking, collaborating, outreach and leadership (e.g. LeDee et al., 2011). Evidence of such skills is required in the majority of funding calls, thus adding to the challenges ECS face when competing for funding with mid- and late-career investigators (Lauer et al., 2017). However, formal graduate programs, or postdoctoral appointments often lack opportunities for ECS to acquire a broad skill set within their academic education, and may not have collaborations with international researchers (e.g. LeDee et al., 2011; Darlington et al., 2015). Therefore, other professional opportunities and networks are essential for ECS to develop and hone their professional skills more broadly.

International Early Career Networks (ECN) are global voluntary communities of ECS whose mandate is to raise ECS

\footnotetext{
${ }^{1}$ For an explanation of all acronyms see Appendix A.

2In this article, we employ the term "Early Career Scientists" but with this equally refer to "Early Career Researchers" and alike.
}

profiles and to train them in skills required by the scientific community. To do so, these networks provide ECS with a large range of training and networking opportunities, such as online or in-person conferences, outreach activities, participation in scientific programs, visibility in large scientific associations, experience in project management (e.g. running the network themselves) and training to acquire grants. ECNs help to address problems facing ECS, for instance, ECS are only rarely involved in reviewing papers (Taylor and Francis, 2015; Silver, 2016), and ECN initiatives have been set up to tackle this (De Vries et al., 2009; Casado et al., 2019). ECN can provide specific training and mentoring directed towards increasing the engagement of ECS with stakeholders and policy makers (Cvitanovic et al., 2015; Timm et al., 2017), for which ECS only have few opportunities (Evans and Cvitanovic, 2018). As another example, ECS may have fewer opportunities to travel to international conferences to meet other scientists and raise their profiles without adequate support and resources, which can be especially difficult for ECS from developing countries. ECN help tackle these issues by providing travel support as well as online opportunities, such as virtual conferences networking activities (Majaneva et al., 2016). In this sense, ECN can be a tool to move beyond barriers and to improve the inclusion of ECS into the international scientific community. Increasingly, representatives of ECN are members of scientific steering committees (SSC) advocating for ECS. These organisations (e.g. Global Research Programmes) are setting aside increasing proportions of funding to support ECS activities.

What is required to create an ECN, either within a specific discipline or across multiple disciplines? What marks the success of an ECN from the perspective of its members? In this article we aim to address these questions to provide insight into the characteristics of successful international ECN by highlighting examples of well-established networks in the polar sciences. We discuss a number of tools to promote and assist ECS, presenting examples of successful activities in this regard. Next, we evaluate structural differences among ECN that work within or across disciplines. To assess the success of ECN, we take into account the results of three surveys conducted on ECN and its members. We also report on our own experiences in ECN. We propose the best practices for developing a successful ECN across Geosciences and related disciplines to inform the creation of new ECN and to improve existing ECN.

\section{Example cases of inter- and intra-disciplinary platforms}

Depending on the scope and background of the members, an ECN can either support ECS within their own scientific discipline or act across multiple scientific disciplines within a certain field, which is a key distinction among ECN. In order to account for this distinctive element we refer to the for- 
mer and latter as "intra-disciplinary" and "inter-disciplinary" platforms, respectively. It is important to note that, while for an intra-disciplinary network the members are all from the one and the same scientific discipline, the respective science is typically and inherently inter-disciplinary (e.g. the example of ice core science below). As science continues to globalize, some inter-disciplinary ECN also go beyond any one field (e.g. Global Academy, Young Earth System Scientists, national Future Earth ECN). Generally, the inter-disciplinary platforms have a larger number of members than the intradisciplinary networks, which requires certain structural differences that are discussed in Sect. 3 below. In this section, we explore examples of well-established inter- and intradisciplinary ECN in polar sciences, to highlight the genesis of the network, its scope, governance mission, and the fundamental deliverables to its members.

\subsection{An inter-disciplinary platform: The Association of Polar Early Career Scientists (APECS)}

The Association of Polar Early Career Scientists (APECS) was founded during the 4th International Polar Year (IPY, 2007-2009) by a small group (Baeseman and Pope, 2011). Initially, there were several intra-disciplinary platforms established around the IPY, including the IPY Youth Steering Committee, the Permafrost Young Researchers Network and the UK Polar Network. Eventually in 2007, representatives of these platforms decided to merge the groups into one large inter-disciplinary network with the name of APECS. Today APECS is an international, inter-disciplinary organisation for ECS working in polar and alpine regions and the wider cryosphere, with 3170 members across the Arctic, Antarctic and the third pole, covering over 30 disciplines in both the physical and social sciences. After the end of the IPY in 2009, APECS obtained financial support for a Directorate, sponsored primarily from the Research Council of Norway, the Norwegian Polar Institute and The Arctic University of Norway. The financial support was crucial to the growth and development of APECS and lasted until December 2016. Since February 2017, the Alfred-Wegener Institute Helmholtz Centre for Polar and Marine Research in Germany has provided financial support for the APECS Directorate. The goals of APECS are to foster the development of international and interdisciplinary collaborations among ECS, to provide support in career development to ECS working in the polar regions and the cryosphere, and to promote education and outreach. The activities and scope of APECS are documented in detail on the APECS website and in a number of publications (Baeseman and Pope, 2011; APECS, 2016; Hindshaw et al., 2018; Xavier et al., 2018).

Today APECS has established Memoranda of Understanding as well as informal relationships with many international organisations involved in Arctic, Antarctic, alpine and cryosphere research, education and outreach. These relationships include Polar Educators International and the Univer- sity of the Arctic, as well as science-focused entities such as the Scientific Committee on Antarctic Research (SCAR) and the International Arctic Science Committee (IASC). At conferences and meeting of these organizations, APECS members are frequently invited to attend and to act as co-chairs to specific sessions. Importantly, APECS collaborates with other ECN and provides support to ECN during establishment and initial phases. The networking with other ECN allows APECS to interact within a broad spectrum of polar research and outreach. In turn, APECS can provide representation and visibility to ECS within the greater polar science community.

Outside of its international network, run by the Directorate, Executive Committee and Council, APECS manages a network of National Committees in over 25 countries. The National Committees follow the general rules and guidelines of APECS, but specifically promote activities, such as outreach programs, seminars and workshops within their countries. National Committees are able to promote capacity building activities for ECS via in-person events, and engage directly with the public and K-12 students via outreach events. These activities often take place in the language of the National Committee's respective country, facilitating local impact. APECS supports such national activities by promoting these events through its communication channels and with small funding contributions, e.g. at workshops to cover the costs of rooms, social dinners etc.. APECS also assists National Committees in their funding applications. Significant examples of education and outreach initiatives of APECS are connected to yearly Polar Week and Antarctica Day activities. Quarterly International Polar Days with a specific theme were eventually expanded into International Polar Weeks, which have been organized by APECS since 2012. Twice a year around the equinoxes, APECS and its National Committees conduct activities such as online class-room connections to field researchers, public lectures and social media activities. APECS and its National Committees regularly organise in-person (e.g. workshops, panel discussions, networking events) as well as online events (e.g. webinars). For example, APECS has organized two world summits: in Sofia, Bulgaria in 2015 and in Davos, Switzerland in 2018. National representatives attended from each of APECS' National Committees, e.g. 41 representatives from 22 countries in the 2018 summit. The latter also included a full day workshop open to all ECS.

\subsection{An intra-disciplinary platform: The Ice Core Young Scientists (ICYS)}

At the first Open Science Conference of the International Partnerships in Ice core Sciences (IPICS) held in 2012 in Giens, France, discussions among senior and young scientists developed around the realization that, compared to other scientific communities, no ECN for young ice core scientists existed to date. A few ECS wrote an open email to the con- 
ference participants to ask for an expression of interest by fellow young ice core scientists to help starting a new ECN, with support from the chairs of the IPICS committee. Based on the responses, a small group of ECS formed what later became the "organizing committee" (OC) of the Ice core Young Scientists (ICYS) network. The group comprised seven ECS, five female and two male scientists, from Australia, Europe and the United States (a mix of postgraduate students and postdoctoral researchers). At the beginning, organizational aspects and the scope of the new network were discussed, using teleconferences at intervals of a few weeks. ICYS developed as an informal, international network of ECS dedicated to ice cores and ice core-related sciences. The main purpose of the network is to foster personal connections among young scientists from around the world, in order to build a supportive ice core science community and to inspire future collaborations. ICYS was entirely self-organized and the OC continues to meet via teleconferences on a regular basis. At the same time, the support of senior scientists at IPICS provided important encouragement and feedback. One of the initial hurdles was to develop a successful communication strategy in order to engage new members and to extend the network. Past Global Changes (PAGES), who supports IPICS through an affiliation, kindly provided the opportunity to set up an ICYS webpage. In this process the OC created an emailaddress and email list, pages on LinkedIn and Facebook as well as a logo of ICYS.

In order to provide its first deliverables to members and to improve the network's visibility, the OC focused on organising informal networking events around large conferences. The first event, an "ice core dinner" was held during the 2013 Fall Meeting of the American Geoscience Union (AGU). Since then, similar events have been organized on a regular basis, e.g. during the SCAR Open Sciences conferences and General Assembly of the European Geoscience Union (EGU). These social events serve to give young scientists a chance for an informal get-together as a basis for building and extending their academic network, and have been widely regarded successes, with typical turnouts of more than 30 ice-core scientists of all ages. ICYS reports its events to the wider community through social media, and through publishing short progress reports in the PAGES magazine (Bohleber et al., 2014). ICYS also has a representative on the IPICS scientific steering committee (SSC) who communicates the ECS perspective to the SSC and shares the activities of IPICS with the ECS ice core community.

In light of these successes, the OC approached organizing a full-day workshop for ECS around the next IPICS Open Science conference held in 2016 in Hobart. Over 85 ECS attended the event, equivalent to about $40 \%$ of the IPICS conference delegation. The high proportion of ECS at the conference was possible through securing funding. ICYS facilitated a total of 64 travel packages for ECS through 5 different funding schemes, including funding specifically for ECS from developing countries. The workshop provided pro- fessional development with panel and break-out sessions. In addition, an exercise in outreach was organized: Short "Frostbytes" presentations for various ice core related topics were created and published as an output in association with "Climate and Cryosphere" (CliC) and APECS. Apart from the panel and break-out discussions, the workshop offered a chance for ECS to build relationships with their peers before the week-long conference began. More details on the past workshop can be found in Bohleber et al. (2016). In order to receive feedback from the participants and the ECS community, questionnaires were handed out at the end of the workshop and later evaluated by the OC (Sect. 3.3). In addition, the workshop offered a chance to attract new members to the OC. The initial success of ICYS was driven by the motivation and perserverance of the first $\mathrm{OC}$ to get the network established.

ICYS is now lead by the second generation of the OC. During an overlap period of several months, founding and new OC members jointly participated in teleconferences, before a part of the founding OC members gradually stepped down. The number of members in the OC remains stable at around 7-10. This number has proven to be a good balance between flexibility and work-load distribution. Presently, the new OC committee is organising the second early-career workshop for the next IPICS Open Science Conference in 2020. An ICYS representative is involved in both the local organizing committee and SSC of the conference. The representative reports back to the $\mathrm{OC}$ regarding the conference and the workshop. As a general target, the OC aims to deliver the ECS workshops at the four-year interval of the Open Science Conferences as one of its major deliverables to the ECS community, together with informal networking events on a quasi bi-annual basis (at e.g. AGU, EGU, SCAR).

\section{Structure of inter- and intra-disciplinary early career networks}

It follows from the differences in size, scope and activities of the example inter- and intra-disciplinary networks illustrated in Sect. 2, that these networks will require unique structures to support their particular purviews. Here we focus on representatives from the polar sciences, in particular APECS, ICYS and the UK Polar Network (UKPN). In order to evaluate their structural differences in a broader context, we conducted a survey among other ECN and obtained feedback from additional representatives of inter- and intra-disciplinary platforms. Furthermore, we conducted additional surveys among members of ICYS and UKPN, respectively (presented in Sect. 3.3), to assess the success of an ECN in view of their structural differences. Ultimately we attempt to find common characteristics of a successful ECN. 


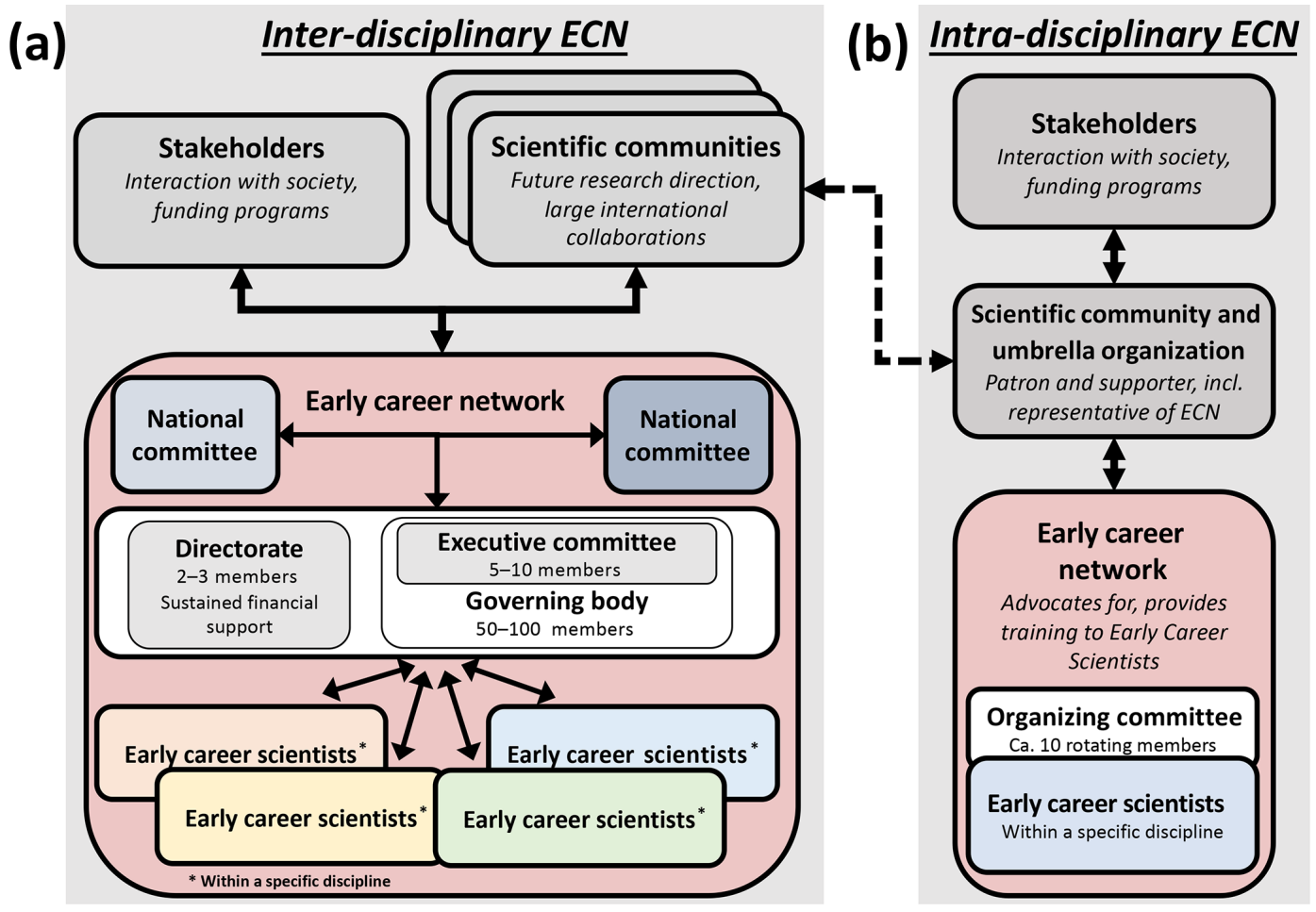

Figure 1. Schematic overview of organizational structure for inter-disciplinary (e.g. APECS) and intra-disciplinary ECN (e.g. ICYS), shown in (a) and (b) respectively.

\subsection{Structure of APECS and ICYS}

The main differences among APECS and ICYS concern the role of an umbrella organization, the existence of permanent funding and staff, as well as the existence of national committees and representatives. Figure 1 summarizes the main structural aspects in a generalized way.

The initial establishment of ICYS took place under the umbrella of a larger scientific community (IPICS) providing essential support. As a small platform, ICYS is characterised by a linear top to bottom structure with strong dependence on an "umbrella organisation" of the scientific community, which acts as a patron to the ECS network (Fig. 1b). Important functions of the umbrella organization include (i) interaction with other scientific communities and disciplines, i.e. the International Association of Cryospheric Sciences (IACS), (ii) discussion and definition of overarching goals as a series of white papers (IPICS, 2019) and (iii) linking between the ECS network and stakeholders. For ICYS, the link with stakeholders such as SCAR or PAGES, or other scientific communities such as the European Partners in Ice Core Science (EUROPICS) is facilitated through IPICS. Importantly, the interaction with the umbrella organization is dynamic and bidirectional by the inclusion of a representative of ICYS in the meetings of the steering committees of IPICS and EUROPICS. Such representation both facilitates the articulation of ECS interests to committees and meetings, as well as providing an important capacity building opportunity for the ICYS steering committee members who take turns acting as representatives of the network. In general, the vertical structure of ICYS offers a dynamic framework for involving many ECS in the interaction with the umbrella organization and for distributing information among the network of ECS. For small to medium size ECS networks with a relatively small steering committee, this structure promotes an effective bridge between the ECS, the ECN and the scientific community.

For larger ECN whose reach extends across disciplines, such as APECS, there is usually not a single umbrella organisation which would exactly match the objectives of the ECN. In the case of APECS, the ECN has grown into an organisation encompassing all research in Polar regions, high mountain areas and the wider cryosphere. As a result of its multiple foci, the structure of the organisation and its link with stakeholders and other scientific communities is rather horizontal (Fig. 1a), in the sense that the ECN will directly interact with a large number of different bodies. Typically in the case of these larger horizontal structures, a larger group of members is required to run the different activities organised by the network. For APECS for instance, the leadership positions include an Executive Committee of 5 members, elected by a Council of 50 to 100 persons, which manages the various project organised by APECS with the help of several paid staff (Directorate). Applications to join the 
Council are accepted throughout the year, though the main period in which new Council members are selected is directly prior to the start of the APECS term in October of each year. Council members participate in Project Groups which encompass the main tasks and the ultimate deliverables to APECS membership and partners over a given Council term. Applications to join the Council of a given year term are voted on by the Executive Committee of the previous year term. Anyone with interest in contributing to APECS leadership can join the council, with no requirement for prior experience with APECS. The current APECS Council contains 103 members from 30 countries. Prior to the start of a new term, the outgoing Council votes on for the new term's Executive Committee among a list of self-nominated applicants. The Executive Committee runs the day to day activities of APECS, manages the large governing Council, oversees Council Project Groups, and works with the Directorate to achieve the APECS' organizational goals to support ECS in the polar domains and promote outreach. Executive Committee applicants often derive from the Council, often having held leadership roles within project groups or the Council itself. Prior experience within APECS or APECS National Committee leadership is a prerequisite for running for the Executive Committee. A President is elected by the Executive Committe from among its five members. Members of the Executive Committee often serve for 1-2 terms, before stepping back into advisory roles in the organization such as Executive Committee or Council ex-officios. The APECS President can only serve one term, but may serve an additional term prior or following their term as president as an Executive Committee member. Council members may re-apply to the Council over multiple terms as they continue to have time to dedicate to the network, and still consider themselves ECS. The typical process for senescence of a member of APECS leadership is to step back into an advisory role (the aforementioned ex-officio roles) for one to several years, before becoming an official APECS mentor, and/or part of the APECS Advisory Committee, a group of more senior scientists who function as an advisory resource for APECS. In all of these ways, APECS works to combat attrition within its governing body and support a strong leadership and advisory team by training and encouraging the promotion of leaders within its ranks, from the Council to the Executive Committee, to finally APECS' advisory bodies.

\subsection{Survey on structure of inter- and intra-disciplinary platforms}

In 2019 we conducted a survey to inquire about structural aspects of ECN. To facilitate participation, a call was sent out via the Future Earth Early Career Network of Networks $(\mathrm{ECNoN})$, a meta-network among various ECN. Through the feedback we were able to cross-examine the structure of five different ECN. Table 1 gives a summary of the results. We find the case of comparatively larger networks with at least a

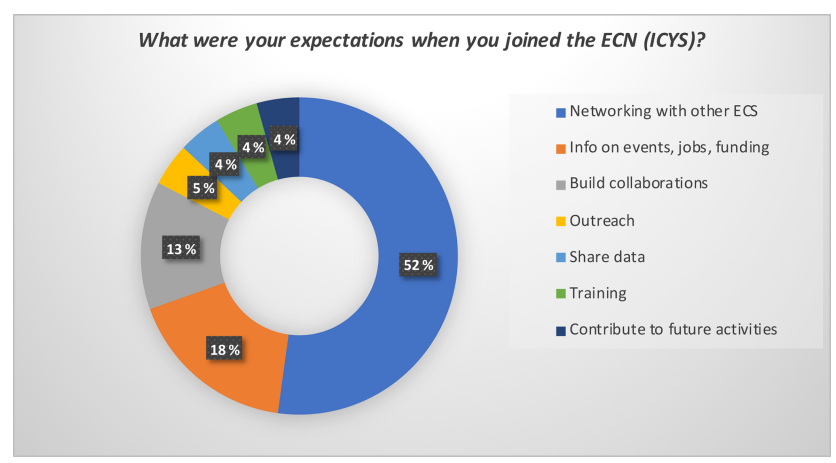

Figure 2. Example survey results showing expectations of ICYS members, given as the number of times mentioned (multiple answers were possible).

few hundred members (APECS, IMECaN and UKPN) and two smaller networks with fewer members, ICYS and the special case of the UN Decade of Ocean Science for Sustainable Development network (UN) (Ryabinin et al., 2019), which is still in a conceptual phase. Recently, an informal task team has been proposed to support with the engagement of Early Career Professionals in the UN Decade of Ocean Science for Sustainable Development. The quantification of the total number of members depends on the procedure of joining the ECN, which is typically done via joining an email-list (e.g. APECS, ICYS). ICYS also has the alternative of joining the respective group on Facebook for discussion and distibution of information (the group size is used in Table 1). Regarding membership, an important decision is whether a certain definition of an ECS is to be used and whether membership is to be restricted only to such ECS. UN and IMECaN employ an ECS definition. For IMECaN this is $<8$ years after graduation, with some flexibility for career breaks (Table 1). For the developing UN network, the current working definition is that professionals are selfidentified early career professionals within 10 years of completing professional training. The large ECN operate within a multi-disciplinary science community, naturally hosting a greater number of potential members. Regarding structural aspects, the large inter-disciplinary ECN (APECS, IMECaN and UKPN) have a executive head as an additional level of organisation to the leadership committee. Some large ECN also have access to a limited but sustained operating budget, for which they report periodically.

\subsection{Evaluating the scope of an ECN with respect to member expectations}

Using ICYS and the UKPN as example cases, we aimed to evaluate if the original scope set by the organizing committee after creation of the ECN aligns with expectations by its members. For the ICYS survey, a call for participation was sent out via the ICYS internal email list (58 members) in September 2019. The response rate $(n=13)$ corre- 
Table 1. Overview of structures in exemplary ECN. For an explanation of acronyms see Appendix A.

\begin{tabular}{lllllll}
\hline Acronym & Number of members & Disciplines & ECS definition & Leadership committee & Executive head & Sustained funding \\
\hline ICYS & 223 & Intra & No & Yes & No & No \\
UN & in conceptual phase & Intra & Yes & - & - & No \\
APECS & 3002 & Inter & No & Yes & Yes & Yes \\
IMECaN & 260 & Inter & Yes & Yes & Yes & Yes \\
UKPN & 376 & Inter & No & Yes & Yes & No \\
\hline
\end{tabular}

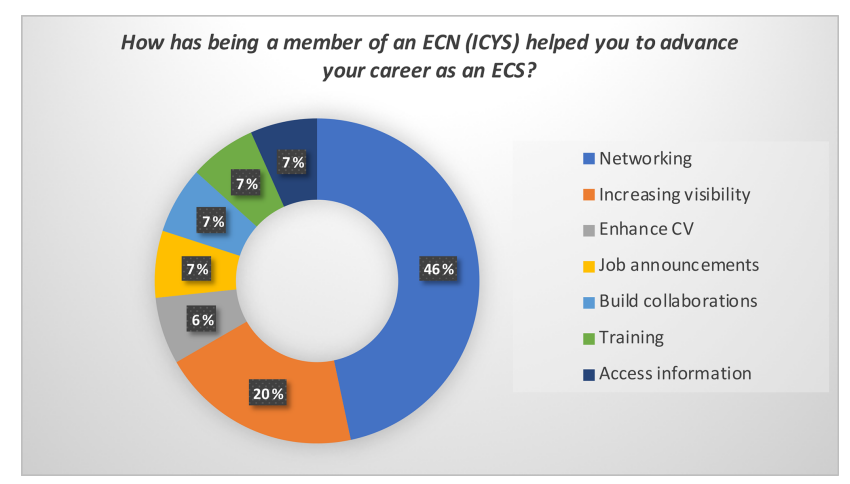

Figure 3. Example survey results showing how an ECN helped the career of ECS (free answers were possible).

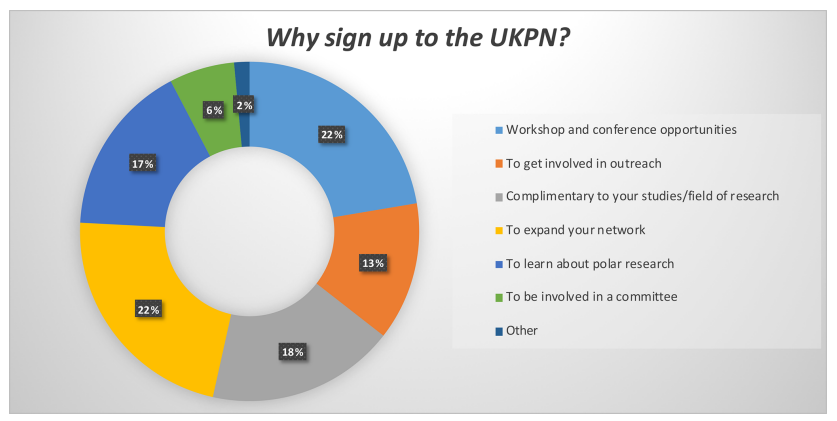

Figure 4. Survey results on why members joined the UK Polar Network.

sponds to approximately $22 \%$ of the members, comparable to and slightly higher than similar surveys conducted among ECN (Hindshaw et al., 2018). Although the absolute number of responses may limit to some extent the representativeness of the survey, we found that the participants provided a good representation of the general membership structure of ICYS: They were split among postdocs $(46 \%), \mathrm{PhD}$ students $(46 \%)$, faculty (one response) and gender (38\% male and $62 \%$ female). It is common for ICYS members to also belong to at least one other ECN (62\%), primarily APECS $(54 \%)$. Figure 2 gives a summary regarding the expectations of our members. The majority ( $84 \%$ ) replied that their expectations have been fulfilled and that their membership in ICYS has helped them to advance their career as a young scientist (Fig. 3). As evident from Figs. 2 and 3, providing the op-

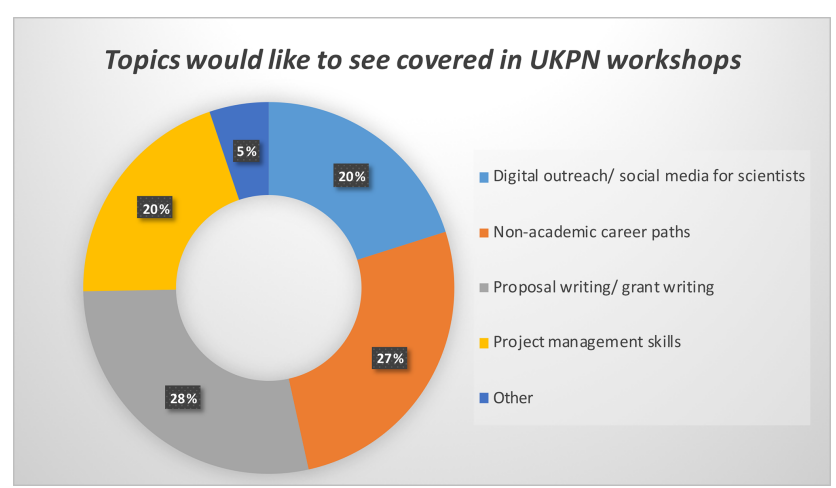

Figure 5. Survey results on what UK Polar Network members would like to see covered in workshops.

portunity for networking among ECS was clearly named as one of the most important tasks for the ECN. All participants noted that they plan to attend the next ICYS ECS workshop organized for the 2020 IPICS Open Science Conference.

The UK Polar Network (UKPN) aims to provide networking and support for ECS, facilitate building of international networks and, provide skills training and information about jobs, conferences, grants, outreach etc. The UKPN also organises education and outreach events, organised and run by ECS. An online members survey was conducted in January 2019 , with 81 participants (around $22 \%$ of our members). Participants were primarily $\mathrm{PhD}$ students $(53 \%)$ and postdocs $(17 \%)$, with fewer numbers that were masters students $(6 \%)$, research scientists $(6 \%)$, faculty, industry, unemployed, or other (4\%), and $2 \%$ undergraduate students. Figure 4 highlights why members joined the UKPN, revealing that most join to expand their network $(22 \%)$ and for workshop and conference opportunities (22\%). Many are members as the UKPN is complementary to their area of research $(18 \%)$, or joined to learn about polar research $(17 \%)$, or to get involved in outreach $(13 \%)$. The responses therefore suggest that the expectations of UKPN members aligns with the aims of the UKPN. To assess the needs of our members, we asked what topics members would like to see covered in the yearly workshops (Fig. 5). Results were split between information on non-academic career paths $(27 \%)$ and proposal/grant writing skills ( $28 \%$ ). Proposal/grant writing was addressed in the 2019 UKPN workshop. Results highlight the 
need to focus not only on academic pathways, but also on the opportunities available outside academia where the skills of ECS would be highly beneficial.

\section{Discussion}

The main aspects of ECN activities can be summarized as: (a) opportunities to raise ECS profiles (e.g. interaction with scientific organisations); (b) training in soft-skills (e.g. through participation in an outreach program or in workshop organisation); (c) advocating for ECS in the scientific community (e.g. via representation in steering bodies); and (d) networking with other ECS and senior scientists, including peer-support and mentoring. The involvement of ECS in ECN relies on voluntary, unpaid time contributed by motivated ECS, who are already under pressure by multiple tasks to advance their career. Thus, it becomes particularly important to recognize the expectations of the ECN members, in order to ensure that the effort is directed toward their needs. This can be achieved through scoping and evaluation, such as by surveys to assess member needs and expectations. However, in the interpretation of the results it has to be borne in mind that the respondees are by definition invested in the organisation and thus may already feel positively about it. Therefore, within the realm of ECS involved in ECN, our surveys can provide information into what member expectations are and if and how these have been fulfilled. From this we draw insights regarding what characteristics make an ECN successful, in the view of ECS.

\subsection{Member surveys and the importance of networking and training}

As the central outcome of the ICYS and UKPN member surveys, it is networking opportunities that make up the most frequent expectations of the ECN. This is consistent with a survey recently conducted among APECS members (Hindshaw et al., 2018). Interestingly, regarding help for advancing their career, ECS part of ICYS give training aspects a reduced recognition as compared to networking and increased visibility. One of the main inherent capacities of ECN is the facilitation of networking among its members. Outside of ECN, ECS are often confronted with obstructions to their ability to network among themselves. Conversely, a large proportion of members of the UKPN joined for workshop and conference opportunities, as well as to get involved in outreach, highlighting a desire for training opportunities. ECN can act to both advertise and disseminate externally organized training opportunities or the organizing committee (OC) can run training events and workshops. Both enable training of ECS, but the capability for the OC to run training events will depend on the time commitments of the current ECN OC.

ECS clearly recognize the opportunities that an ECN can provide as a complement to their every-day academic envi- ronment. We find this documented in several instances in the anonymous feedback forms that were handed out after the ICYS ECS workshop held in Hobart in 2016. Based on feedback forms, the event in general, but also the structure with plenary and break-out sessions was very well received by the attendees. Many attendees remarked that meeting other ECS before the main meeting improved their conference experience and sense of involvement in the community. This is consistent with surveys from previous studies showing that mentoring programs such as pre-conference workshops can reduce the feeling of isolation and assist taking on an active conference participation (Adams et al., 2016). As concrete examples from our feedback forms, the responses to the question "What parts of the workshop did you find most useful, and why?" were "The science communication part. We have very few opportunities to learn about it while it becomes a more important part in science." and "Panel discussion on the future of ice core sciences. As young scientists we lack knowledge about the big picture research trends. It is really helpful to get some ideas from the experienced scientists." The latter comment provides a clear example of how ECN help to propel ECS into taking an active role in shaping the future direction of their research field. Regarding the perspective of the individual ECS, their peer network can provide a subjectively safe environment for exploring new skills and becoming connected with fellow ECS (Hindshaw et al., 2018). The broad set of transferable skills in communication and management are typically not part of the standard education of ECS in academic environments, but are of great value in addition to their specific academic skill set (Weiler, 2007; Gordon, 2014; Darlington et al., 2015). The demand for training in project management skills is highlighted in the UKPN survey (Fig. 4). Experience in science communication and outreach is one of the many transferable skills that are fostered by ECN and have a broader impact on society. These skills are beneficial to the individual ECS, but also have a positive impact on the scientific community through the inspiration of the next generation of scientists. Local communities benefit from ECN, such as, through the school visits facilitated by the UKPN. By linking up schools with ECS, and providing guidance to the ECS, the UKPN help develop skills of the ECS, but also benefit the school. The latter comes through demonstrating applications of the pure sciences taught at school, as well as through access to novel and engaging science, tighter connections to academia and exposure to the wide variety of scientists and their careers. The latter point is particularly relevant for under-represented groups. The UKPN has received unanimously positive feedback, with schools finding the visits engaging, relevant, and a benefit to the pupils.

\subsection{Commitment of members in leadership roles}

Apart from addressing the expectations of the members, other structural aspects impact the success of an ECN. An 
almost self-evident yet crucial point, the core of the ECN, e.g. the organizing committee, has to have dedicated, driven and enthusiastic members. The time commitment is often voluntary, and so success of an ECN relies on the maintained enthusiasm of the committee. With changing committee members (every 1-4 years for the ECN discussed here), the outputs of ECN can also change to reflect the particular passions of the current committee. For example, the UKPN typically facilitates more school visits in a year when the committee is comprised of multiple members with an interest in outreach. A diverse committee is therefore important for maintaining a well rounded set of ECN aims to support ECS.

In order to be successful, there is a critical mass required for an ECN. An ECN needs sufficient membership to provide a networking platform, establish critical mass to support activities, and to be self-supporting. The UKPN relies on it's members as a volunteer pool to support outreach events, enabling the UKPN to both provide training and experience in outreach, whilst also benefiting local communities through these events. The member base needs to be large enough for the ECN to be beneficial to all, but there needs to be a single, well-defined theme that connects members, yet, in the case of inter-disciplinary networks, still allows for a range of specialisms. An ECN consisting of a large number of members does not necessarily necessitate a large organising committee. The example of ICYS demonstrates that the demand of the ECS community for a dedicated networking platform can be met by small and self-supportive ECN. In case of ICYS it is sufficient to have only one organizational body apart from the general membership, e.g. an organizing committee with less than 10 members, with support by an umbrella organization (e.g. IPICS, in the case of ICYS). Dedicated networking events and workshops, taking place around large conferences, can be organized through small but sustained commitment of the OC members. The positive member feedback supports the success of this organizational strategy. In addition, the use of social media platforms like Facebook and Twitter allows the ECN to effectively share information, e.g. on events and job announcements. The involvement of ECS in the organizing committee of an ECN offers various training opportunities in career-relevant soft skills. The latter include the organization of workshops and meetings, outreach activities (e.g. reporting about the events via social media or articles in the PAGES magazine) and also proposal writing skills for acquiring funding for events. A particular opportunity to gain experience in governance is to represent the ECN within external steering committees, such as the umbrella organisations. ICYS has been asked to nominate representatives to organizations, such as the European Partners in Ice Core Science (EUROPICS). The periodic rotation of representatives to the steering committees of the International Partners in Ice Core Science (IPICS) and EUROPICS ensures that this training opportunity is shared among members of the ECN.

\subsection{Rotation of members in leadership roles}

Evidently, the need to periodically regenerate members of the $\mathrm{OC}$ is a crucial point in the lifetime of an ECN. Being naturally transitory, ECS can move on to become permanent faculty, leave academia or simply lack the time to contribute to OC. These former members of the ECN and OC can provide valuable expertise and institutional links through maintaining an informal association with the ECN. Results of the UKPN member survey showed that $4 \%, 4 \%$ and $6 \%$ identified their career stage as faculty, industry or research scientist respectively, highlighting continued involvement with ECN. On the other hand, comparatively small intra-disciplinary platforms such as ICYS are at risk of becoming dormant or even abandoned, due to attrition and inadequate recruitment and sustained engagement of its members and OC. Regarding the first generation change in the OC of ICYS, the four-year cycle of IPICS Open Science conferences has provided a useful interval for recruiting new OC members. The in-person meeting of the OC in order to organize the ECS workshop at the end of the first four-year interval was of critical importance to new ECS recruitment to the OC. At the same time, a four-year cycle is still within the range of an ECS. Importantly, shorter intervals have proven to work, especially for networks with a larger membership, e.g. the UKPN changes its steering committee every year. This shorter interval can help prevent ECN dormancy, as it can be easier to recruit new members of the $\mathrm{OC}$, particularly $\mathrm{PhD}$ students or postdocs on short-term contracts, who would not be able to commit to a four-year period. However, with this shorter cycling of the committee comes the need to ensure continuity from one year to the next. For the generation change in the ICYS $\mathrm{OC}$, an overlapping period with a mixture of old and new OC members participating in the $\mathrm{OC}$ meetings has proven useful to delegate tasks and ensure continuity in activities. Other ECN operate on a combined scheme, e.g. an initial 2-year term with the option to extend once without the need for vote from wider members. This may provide flexibility for OC members to adjust their commitment accordingly, e.g. due to limited time availability in the final phase of a $\mathrm{PhD}$.

\subsection{Workload management}

Based on the unchanged size of the ICYS OC after the generation change, it appears that a typical size of 10 OC members provides an appropriate balance between mobility and individual workload. This OC membership number allows for the typical workload of an OC member of ICYS to remain manageable for any given ECS, e.g. a few hours per month, with peaks around specific events.

The large participation of ECS in APECS from various disciplines studying the polar regions attests to the success of this association, while additional requirements arise to address the needs of a larger membership. The time commitment of each OC member is a crucial constraint in this re- 
gard, as ECS are under particular pressure to commit to their scientific projects, publications, laboratory and field work etc. As the ECN grows in size, this fact introduces an important issue of inertia. Once a critical size is reached that requires a higher level of activity, it is likely that meeting the demands of its members will become increasingly difficult for the steering committee. Accordingly, it eventually becomes essential to have a permanent staff who can support activities and management.

The APECS International Council manages its workload by dividing Council members into Project Groups (PG) (APECS, 2019). Council members choose which PG they would like to join, and choose a PG leader (PGL) among themselves. The PG creates a proposal at the beginning of the Council term that is reviewed by the Executive Committee. This proposal outlines the PG's goals, deliverables, timeline, and task allottment. The Executive Committee works with the PG to assure that their proposal outlines an achievable set of goals. PG can be suggested by Council members, and may continue between one term and the next if interest remains. Some PG, like those which run the annual outreach activities of the Polar Weeks, Antarctica Day, and the annual capacity building and networking activity of the Online Conference, occur every year. Other PGs, such as the NonAcademic Careers Information group, define their goals each year based on the interests of the Council members participating in the group. Further other groups exist for a set period to achieve a set task (i.e. reviewing the content and organization of the APECS website), or are geared towards the planning and preparation of an event at an International conference (i.e. an APECS event at the Scientific Committee on Antarctic Research (SCAR) or the General Assembly of the European Geoscience Union (EGU)). PG meet monthly or bi-monthly to discuss their project, and have access to specific google folders in which to organize their work. PGL meet every two months in online meetings to discuss general questions and concerns regarding group management, and also to collaborate on synergistic activities (i.e. survey development). Executive Committee members also help to advise PG, respond to their queries, and keep them on track to reach their desired goals. PG are advertised on the APECS website, and any APECS member (even those not involved in the Council) are welcome to take part in the activities of any given PG. The PG structure allows for the efficient and effective participation of Council members in APECS, and allows for the APECS leadership to develop a clear set of deliverables to their ECS membership.

\subsection{Financial support}

Financial support plays a key role for the success of ECN, especially for maintaining a sustained organizational body with the assistance of staff in larger ECN. In order to make any training events equally accessible for ECS, external funding is required to support costs associated with travel, inciden- tals, programming, and other fees associated with the trainings or workshops. The funding may be distributed across various organizations and programs that may support unique aspects of the program. Some organizations may support travel for some participants, while others may sponsor meals and training costs. For instance, successful fundraising activities were fundamental to realizing the ICYS ECS workshop in 2016, in particular to raise support for awarding travel grants to ECS. Additionally, support from the UK Foreign and Commonwealth Office has allowed the UKPN to run successful ECS workshops each year for the past few years, as well as supporting outreach events such as school visits. Without this financial support these training opportunities for ECS, with outreach also having a positive impact on local communities, would not be possible. It is essential that there is sustained funding year on year to support ECN and enable the continued support, training and development of ECS.

\subsection{Key points for building and maintaining an ECN}

To successfully set up the intra-disciplinary ECN ICYS it was crucial to be part of a well-defined community under the umbrella of IPICS and with additional support, e.g. by PAGES. Similarly, the UKPN sits under APECS, receiving organisational support as well as access to a wider network. With regards to the examples of ICYS and the UKPN, the following components are important during the initial phase of an ECN: (i) a well-defined scope; (ii) a leadership committee (incl. generation changes); (iii) an initial event (e.g. workshop) to get the network widely recognized; and (iv) strong support from SSC/community. In order to successfully maintain long-term an ECN, the following points can be identified based on the the success of APECS: (i) financial support for long-term operation of the network (venue, administration, funding); (ii) establish national and/or discipline specific sub-committees to host networking and engagement events, such as the Project Group Structure; (iii) provide regularly networking activities and support for ECS (iv) organise education and outreach opportunities for ECS; (v) provide information for jobs, conferences, outreach, grants etc.; (vi) facilitate workshops and building of international networks; and (vii) offer doctoral training, summer schools.

\section{Conclusions}

What makes an ECN successful? While it remains difficult to provide a comprehensive answer to such a general question, we have considered here examples of successful interand intra-disciplinary platforms, APECS, UKPN and ICYS. With the additional help of three surveys among ECN and their members, it is possible to draw the following generalized conclusions, which we propose as relevant to a bestpractice approach in ECN: 
1. Structure. Mainly due to the size of their memberships and their inter- and intra-disciplinary community, the two networks have a distinctly different structure. An intra-disciplinary network such as ICYS, benefits from a "vertical" structure with immediate support by an umbrella organization (IPICS). In order to facilitate bidirectional exchange, it is important to integrate a representative of the ECN in the steering committee of the umbrella organization. This provides a voice and representation within the supporting and partner institutions along with promoting the interaction of ECN with stakeholders and other scientific communities. In the case of a larger inter-disciplinary network, this interaction takes place directly, owing to its more "horizontal" organizational scheme. The inter-disciplinary network clearly relies on having sustained financial support for its longterm operation and from the management structure of its leadership body, and the integration of national chapters.

2. Member scoping, evaluation, and adaptation. As an ECN can only survive long-term if the expectations of its members are met, an important part of a best-practice approach is to evaluate member expectations and feedback, e.g. via a survey. The survey conducted among ICYS and UKPN members indicated that members expected to gain opportunities and experiences from ECN that would be otherwise difficult to achieve in their academic environments. First and foremost, this concerns all aspects of networking among fellow ECS as well as with senior scientists. Other important aspects concern training in various soft-skills and increasing their own visibility among the scientific community, e.g. via representing the ECN in a scientific steering committee. As demonstrated from the surveys among UKPN and ICYS, we find that if the demand for networking, increased visibility and other objectives aligns well with the scope set originally for the ECN, this greatly adds to the general success of the ECN.

3. Continuity of organizing committee representation. Due to the temporary nature of the early-career stage, the long-term success of a small ECN crucially depends on recruitment between generations of its organizing committee. A four-year cycle with a transition period has proven successful for the first generation change in ICYS, but shorter time periods may be more adequate, especially to networks with larger memberships. UKPN uses a one-year cycle, which is also well within the duration of a $\mathrm{PhD}$ thesis.

4. Diverse membership. By soliciting membership across the many disciplines associated with polar and cryosphere research, APECS has been successful in building a diverse network of ECS. Recruiting to leadership positions from across this diverse network allows for a representative leadership structure, and enhances networking opportunities among the APECS Council. The management of the Council by the Executive Committee provides bidirectional training opportunities for both groups and facilitates the work of the Council, while the mentorship and support by the Directorate promotes the training of the APECS leadership, and its deliverables to the APECS membership. APECS' relationships with important international partners allows them to further advocate for ECS by encouraging the inclusion of ECS in partner steering committees, meetings and conferences, as well as by the distribution of funding in the form of travel support and scholarships to the ECS community. These partnerships include collaboration on international and European funding schemes, through which APECS runs training schools for ECS. The APECS website, maintained by the Directorate, serves as a hub for partners and members, where event announcements and reports, job and funding opportunities, and many more resources are made accessible to the wider polar community. APECS' leadership structure, which builds in the training and recruitment of its future leaders, provides and important source of stability to the organization, reducing attrition and promoting the capacity building of the greatest representation of ECS.

Overall, Early Career Networks provide fundamental support to the development of early career professionals in scientific and related disciplines and connect professionals within and between disciplines around the world. Well-established and long-term networks, such as APECS, UKPN and ICYS, can provide valuable case-studies to better understand the attributes that make an ECN sustainable. In this view, addressing the above outlined characteristics with respect to structure, member scoping, continuity of organization and diverse membership are vital to ensuring a successful and sustained $\mathrm{ECN}$ and can inform the development of future ECNs. 
Appendix A: Acronyms used in the text

$\begin{array}{ll}\text { AGU } & \text { American Geoscience Union } \\ \text { APECS } & \begin{array}{l}\text { Association of Polar Early Career Scien- } \\ \text { tists }\end{array} \\ \text { CliC } & \text { Climate and Cryosphere } \\ \text { ECN } & \begin{array}{l}\text { Early Career Network } \\ \text { ECNoN }\end{array} \\ & \begin{array}{l}\text { Future Earth Early Career Network of Net- } \\ \text { works }\end{array} \\ \text { ECS } & \text { Early Career Scientist } \\ \text { EGU } & \text { European Geoscience Union } \\ \text { EUROPICS } & \text { European Partners in Ice Core Science } \\ \text { IACS } & \text { International Association of Cryospheric } \\ & \text { Sciences } \\ \text { IASC } & \text { International Arctic Science Committee } \\ \text { ICYS } & \text { Ice Core Young Scientists } \\ \text { IMECaN } & \text { Interdisciplinary Marine Early Career Net- } \\ & \text { work } \\ \text { IPICS } & \text { International Partners in Ice Core Science } \\ \text { IPY } & \text { International Polar Year } \\ \text { OC } & \text { Organizing committee } \\ \text { PAGES } & \text { Past Global Changes } \\ \text { PG } & \text { Project Groups } \\ \text { PGL } & \text { Project Group Leader } \\ \text { SCAR } & \text { Scientific Committee on Antarctic Re- } \\ & \text { search } \\ \text { SSC } & \text { Scientific Steering Committee } \\ \text { UKPN } & \text { United Kingdom Polar Network } \\ \text { UN } & \text { United Nations Decade of Ocean Science } \\ & \text { for Sustainable Development Network } \\ & \end{array}$

\section{Appendix B: Questions and answering options of ECS}

Possible answering options are given in parenthesis.

\section{B1 Survey among ICYS members}

- What is your career stage? (Student, PhD student, Postdoc, Faculty, Other)

- Are you a member of any other early career network? If yes, which network? (free answer)

- Are you a member of any other early career network? (yes, no) If yes, which one? (free answer)

- What were you main expectations when you joined ICYS? (free answer)

- Have these expectations been fulfilled by participating to ICYS? (yes, no). If yes, how? If no, what do you think is missing in this network to do so? (free answer)

- Did you go to the previous ICYS workshop in Hobart in 2016? (yes, no). If yes, do you have any remembrance worth sharing? (Good or bad, any feedback is welcome). (free answer)
- Are you planning to attend the next ICYS workshop at the 2020 IPICS OSC? (yes, no, maybe)

- Is there anything else you would like to share with us? (free answer)

\section{B2 Survey among UKPN members}

The following questions were part of a larger survey conducted in 2019 and were re-evaluated as part of this study:

- Career Stage

- Doctoral student

- Undergraduate student

- Masters student

- Faculty

- Postdoctoral researcher

- Industry

- Unemployed

- Research scientist

- Other

- Why did you sign up to the UKPN? (select all that apply)

- Workshop and conference opportunities

- To get involved in outreach

- Complimentary to your studies/field of research

- To expand your network

- To learn about polar research

- To be involved with the committee

- Other

- What topics would you like to see covered in a UKPN early career scientist workshop in 2019? (please select all that apply)

- Digital outreach/social media for scientists

- Non-academic career paths

- Proposal writing/grant writing

- Project management skills

- Other 
Data availability. All the underlying data is in the manuscript - we have included the conducted surveys in the Appendix, and in the text report for each survey the total number of participants. If multiplied with the percentages used in the figures, this gives the total number of responses.

Author contributions. The survey among ECN and ICYS members was conducted by PB and MC with the help of AS and VHLW. The survey among UKPN was conducted by $\mathrm{AB}, \mathrm{HEJ}$ and $\mathrm{CAB}$. PB and $\mathrm{MC}$ wrote an initial draft of the manuscript. All authors contributed to writing the final version of the manuscript.

Competing interests. The authors declare that they have no conflict of interest.

Special issue statement. This article is part of the special issue "Diversity and equality in the geosciences (EGU2019 EOS6.1 \& US4, AGU2018 ED41B, JpGU2019 U-02)". It is not associated with a conference.

Acknowledgements. The authors would like to thank all participants of the surveys for providing their input. We would also like to thank our ECN for their support. We further thank the ICYS organizing committee for supporting the initial idea of this manuscript and for convening members from various ECN. Thanks to the Global Environment Research Committee (GERC) and the Royal Society for bringing ECS together to discuss ECN interactions within the geoscience community during the one day GERC-Future Earth meeting in February 2019, London.

Financial support. Pascal Bohleber has been supported by the European Union's Horizon 2020 research and innovation programme under the Marie Skłodowska-Curie grant agreement No. 790280. Mathieu Casado and Jilda Alicia Caccavo have been supported by the Alexander von Humboldt Foundation in the form of Humboldt Research Fellowship for Postdoctoral Researchers. Kirsti Ashworth has been supported by the Royal Society of London for funding her Dorothy Hodgkin Research Fellowship (grant no. DH150070). V. Holly L. Winton was supported by a Rutherford Foundation Postdoctoral Fellowship administrated by the Royal Society Te Apārangi. The UKPN receives funding from the Foreign Commonwealth Office through the British Antarctic Territory and is in partnership with the Challenger Society.

The article processing charges for this open-access publication were covered by a Research Centre of the Helmholtz Association.

Review statement. This paper was edited by Chiaki Oguchi and reviewed by two anonymous referees.

\section{References}

Adams, A. S., Steiner, A. L., and Wiedinmyer, C.: The earth science women's network (ESWN): Community-driven mentoring for women in the atmospheric sciences, B. Am. Meteorol. Soc., 97, 345-354, 2016.

APECS: APECS Strategic Plan 2016-2020, APECS website, https://doi.org/10.5281/zenodo.1477872, 2016.

APECS: APECS Council Project Groups, APECS website, available at: https://www.apecs.is/who-we-are/leadership/council/ council-project-groups.html (last access: 29 November 2019), 2019.

Baeseman, J. and Pope, A.: APECS: Nurturing a New Generation of Polar Researchers, Oceanography, 24, 219, 2011.

Bohleber, P., Cavitte, M., Koffman, B., Markle, B., Pavlova, P., Winstrup, M., and Winton, H.: Ice Core Young Scientists, Past Global Changes Magazine, 22, 96, 2014.

Bohleber, P., Cavitte, M., Koffman, B., Markle, B., Pavlova, P., Winstrup, M., and Winton, H.: Ice Core Young Scientists workshop, Past Global Changes Magazine, 24, 49, 2016.

Casado, M., Gremion, G., Rosenbaum, P., Caccavo, J. A., Aho, K., Champollion, N., Connors, S. L., Dahood, A., Fernandez, A., Lizotte, M., Mintenbeck, K., Poloczanska, E., and Fugmann, G.: The benefits to climate science of including Early Career Scientists as reviewers, Geosci. Commun. Discuss., https://doi.org/10.5194/gc-2019-20, accepted, 2019.

Cvitanovic, C., Hobday, A., van Kerkhoff, L., and Marshall, N.: Overcoming barriers to knowledge exchange for adaptive resource management; the perspectives of Australian marine scientists, Mar. Policy, 52, 38-44, 2015.

Darlington, E., Waite, C., and Balsdon, S.: Postgraduate events as a building block for interdisciplinary research, Area, 47, 481-483, 2015.

De Vries, D. R., Marschall, E. A., and Stein, R. A.: Exploring the peer review process: what is it, does it work, and can it be improved?, Fisheries, 34, 270-279, 2009.

Evans, M. C. and Cvitanovic, C.: An introduction to achieving policy impact for early career researchers, Palgrave Communications, 4, 1-12, 2018.

Gordon, W.: Developing Scientists' "Soft" Skills, Eos, Transactions American Geophysical Union, 95, 55-55, 2014.

Hindshaw, R. S., Mariash, H., Vick-Majors, T. J., Thornton, A. E., Pope, A., Zaika, Y., Lenz, J., Nielsen, H., and Fugmann, G.: A decade of shaping the futures of polar early career researchers: A legacy of the International Polar Year, Polar Rec., 54, 312-323, 2018.

IPICS: IPICS White Papers, PAGES website, available at: http: //pastglobalchanges.org/science/end-aff/ipics/white-papers, last access: 29 November 2019.

Lauer, M., Tabak, L., and Collins, F.: Opinion: the next generation researchers initiative at NIH, P. Natl. Acad. Sci. USA, 114, 11801-11803, 2017.

LeDee, O. E., Barnes, R. T., Emanuel, R., Fisher, P. B., Henkel, S. K., and Marlon, J. R.: Training a new scientist to meet the challenges of a changing environment, Eos, Transactions American Geophysical Union, 92, 135-136, 2011.

Majaneva, S., Hamon, G., Fugmann, G., Lisowska, M., and Baeseman, J.: Where are they now? - A case study of the impact of international travel support for early career Arctic researchers, Polar Sci., 10, 382-394, 2016. 
Ryabinin, V., Barbière, J., Haugan, P., Kullenber, G., Smith, N., McLean, C., Troisi, A., Fischer, A., Aricò, S., Aarup, T., Pissierssens, P., Visbeck, M., Enevoldsen, H. O., and Rigaud, J.: The UN Decade of Ocean Science for Sustainable Development, Front. Mar. Sci. 6, 470, https://doi.org/10.3389/fmars.2019.00470, 2019.

Silver, P.: Advice for early-career peer reviewers and authors responding to peer reviews, Freshw. Sci., 35, 1073-1075, 2016.

Taylor and Francis: Peer review in 2015: A global view. A white paper from Taylor and Francis, Taylor and Francis, available at: https://authorservices.taylorandfrancis.com/peer-review/ peer-review-global-view/ (last access: 29 November 2019), 2015.
Timm, K., Pope, A., Smieszek, M., Fugmann, G., and Zaika, Y.: Arctic science: From knowledge to action, The Polar Journal, 7, 428-429, 2017.

Weiler, C. S.: Meeting Ph. D. graduates' needs in a changing global environment, Eos, Transactions American Geophysical Union, 88, 149-151, 2007.

Xavier, J. C., Azinhaga, P. F., Seco, J., and Fugmann, G.: International Polar Week as an educational activity to boost scienceeducational links: Portugal as a case study, Polar Rec., 54, 360365,2018 